Article

\title{
Navigating Sustainability Embeddedness in Management Decision-Making
}

\author{
Catherine Le Roux * and Marius Pretorius \\ Department of Business Management, University of Pretoria, Pretoria 0083, South Africa; \\ marius.pretorius@up.ac.za \\ * Correspondence: catherineleroux24@gmail.com; Tel.: +27-124-298-688 \\ Academic Editor: Giuseppe Ioppolo
}

Received: 28 February 2016; Accepted: 28 April 2016; Published: 5 May 2016

\begin{abstract}
Sustainability is an essential theme for business. In order to compete, strategies need to be improvised and efficient and effective decisions need to be made for improved sustainability performance. Despite management's apparent knowledge of this, it appears that challenges persist with sustainability's embeddedness in decision-making and its implementation in practice. In this study we propose a metaphor applying an integrative view of sustainability as support for management. We offer six antecedents of sustainability embeddedness in decision-making that contribute to building and confirming theory, and also provide a better understanding of current practice around sustainability embeddedness so that strategies can be developed for improved sustainability performance. Employees on all management levels in a stock exchange listed company provided rich empirical data for the study. Through the analysis of data in a case study, antecedents were inductively identified, conceptualized, and presented as using descriptive labels, namely: A True North Destination-a vision of sustainability embeddedness; Mountains-three obstacles; Fog_confusion and complexity; Myopia—shortsightedness; Navigation Necessities-requirements for the journey; and finally, the Chosen Team-selected stakeholders. Sustainability embeddedness was found to be dependent on leadership, the strategy message and structures, performance measures, and policies that support a unified culture for sustainability embeddedness.
\end{abstract}

Keywords: sustainability; embeddedness; decision-making; sustainable decisions; integrative view; metaphor; antecedents

\section{Introduction}

The case for sustainability's place in business has long since been made [1-5]; we have seen a shift in discourse from asking "should we incorporate sustainability?" towards asking "how can we incorporate it?" and, most recently, discourse on "how can we do it better?" While the dialogue has clearly evolved, concerns remain that sustainability may not be as embedded in decision-making as desired, and challenges exist with implementation. Authors Waas et al. [6] agree, purporting that sustainability needs to move "beyond the rhetoric," and expressing a need to "actually realize sustainable development." In this paper we maintain that in order to contribute towards better, more efficient, and effective decision-making for improved sustainability performance in industries, attention should first be directed towards the current status of sustainability's embeddedness in decision-making.

Sustainability is commonly recognized as the internalization of social and environmental issues into business operations and in engagement with stakeholders [7-9]. The realization of sustainable development-a term often used interchangeably with sustainability-requires its embeddedness into the organization's "strategy fabric" so that it forms part of the value creation process and a vital part of how the organization ensures its future resilience and performance $[8,10,11]$. For sustainability embeddedness to occur, an organization needs to instill sustainability into organizational goals, core 
managerial processes, and functions and responsibilities [12-14]. Sustainability needs to permeate throughout the organization and form part of practitioner practices, beliefs, and decision-making at every level [15-18]. Embeddedness entails merging environmental and social sustainability with existent economic and financial decision-making. Sustainability embeddedness requires not only leadership's intervention and the creation of an embedded culture, but also changes to organizational arrangements in order to support the making of sustainable decisions [10,14-16]. These changes should facilitate employee unity and commitment towards corporate goals and action in decision-making, which in turn leads to long-term profit and growth [14,19].

Sustainability adoption is often portrayed as a journey from stages of rejection and non-responsiveness towards sustainability, to maturing and becoming an industry and global leader that has embedded sustainability into their strategy and decision-making [8,20]. Organizations that show evidence of sustainability embeddedness and sustainable practices are described as being in the sustainable organization stage of adoption $[8,14,21]$. Sustainable organizations take an integrative view of sustainability that supports the idea of the inclusive, holistic, and simultaneous incorporation of all the elements of sustainability and the interests of a wider stakeholder group $[8,22,23]$. This view maintains a widely shared and embedded focus towards long-term growth and performance, by considering all the elements of sustainability equally and interdependently $[9,19,20,24]$.

In contrast to sustainable organizations, organizations in the early stages of sustainability adoption mostly ignore the notions of sustainable development, or, at the minimum, adhere to legal requirements imposed on them $[8,25]$. Organizations in these early or intermediate stages of sustainability adoption are often characterized by a short-term view of business that focuses on the financial bottom line or business-as-usual associated with a shareholder-centric philosophy $[8,19,21,25]$. Even though some organizations develop to become proactive about social and environmental responsibility, many of these organizations still embrace an institutional view of sustainability, also called a "Friedmanesque view" or "business case" approach. This institutional view purports that the interests of society and the environment should only be considered when they contribute towards enhanced financial performance $[2,3,26]$. Most studies on sustainability adoption have focused on proactive organizations and the operational changes necessary to create a more socially and environmentally responsible organization $[20,27]$. As indicative of this special issue, interest in corporate sustainability has developed beyond proactivity and beyond the business case for it, towards an integrative view where the planet, people, and profit are considered together. Much of sustainability research has focused on the institutional view that seeks out win-win situations that prioritize the shareholder and survivability [14,27-29]. Only a few researchers in the field of sustainability have adopted an integrative embedded stance in studies, or conceptualized corporate contributions to sustainable development beyond the business case for it $[2,7,8,18]$. This highlights the importance of research embracing this approach.

\section{Background and Research Purpose}

Engagement with managers during studies in practice and industry reveals that sustainability may not be as embedded-engrained—in decision-making as is desired [8,30,31]. For instance, managers have raised concerns that corporate sustainability practices do not reflect a comprehensive view of sustainability or any values beyond profit. Managers have observed that risk assessments and decision-making outcomes do not always reflect an inclusion of all the elements of sustainability or of a broader group of stakeholders. Even though sustainability has secured its place as a permanent fixture on the management agenda and there is a growing resource base supporting sustainability, it appears that the current state of sustainability embeddedness differs from the expected state. In fact, the absence of knowledge about the current embeddedness situation appears to be hindering the achievement of desired levels of sustainability embeddedness and performance [4,32-35]. An implementation gap between actual and desired levels of sustainability embeddedness has been confirmed by the literature and has been described as "problematic" given the importance of sustainability $[6,30,36,37]$. 
The reality is that sustainability-embedded decision-making presents numerous challenges for practitioners-individual actors in practice-and sustainability continues to be interpreted in a somewhat random fashion $[38,39]$. This arguably inhibits sustainability's practical realization. For instance, sustainability embeddedness calls for all practitioners to make a paradigmatic shift in their decision-making from prioritizing a single financial goal and shareholders (business case view) $[2,3,5,26]$ towards focusing on a shared goal of financial, social, and environmental sustainability that considers multiple stakeholders and their needs (integrative view) $[8,14,19,40]$. As a result, sustainability-embedded decisions (used interchangeably with sustainable decisions) have been described as multi-dimensional, in that practitioners need to manage often competing stakeholder objectives, and deal with trade-off situations where there are various tensions [7,41,42]. While trade-offs are commonplace in corporate decision-making, they contribute to greater complexity when it comes to sustainability embeddedness [12,43]. In the process of making sustainable decisions, practitioners run the risk of finding a solution to one element of sustainability that could be detrimental to that of another. Furthermore, sustainability-embedded decisions have been described as contextual, value-laden, and bounded in terms of human rationality [44]. As such, managers do not always have a complete understanding of strategic situations but, rather, have subjective representations of the context that drives their decisions and practices [45]. Additionally, authors Andersson and Bateman [46] note that practitioners often have little or varying amounts of environmental education and training, which influences their decision-making. Practitioners are also expected to make long-term sustainable decisions, often in short time frames, amid open-ended objectives [9,41]. Corporate decision makers face a great deal of ambiguity in understanding sustainability issues and how their organization is affected by these issues, and therefore struggle to respond to these issues [42,46]. This is exacerbated by the fact that there appears to be a lack of agreement and clarity about sustainability's definition $[47,48]$.

Studies in the fields of sustainability and decision-making have often focused on supporting practitioners to make optimal or, alternatively, rational decisions pertaining to sustainability [49-51]. The purpose has been to gather information and accurately align it with sustainable development goals to help practitioners make better and clearer decisions for sustainability $[6,43,52]$. This approach to decision-making mostly focuses on addressing the question "what should we do?" so as to ensure the likelihood of a good and sustainable outcome [53]. Research has contributed towards improved decision-making for sustainability through the development and application of mathematical practices, tools, software, and methodologies for supporting and structuring decisions [43,44]. Many of the approaches in this field include multi-criteria decision-making methods and analytic models to deal with the process of making decisions $[45,54]$. While these studies offer valuable decision-making support to practitioners, it is recognized that to fully realize and improve sustainability embeddedness in decision-making, research needs to go beyond mathematical or technical descriptions and that which may be quantifiable or measureable $[6,41,43,44]$. It is therefore necessary to consider other approaches to pursue greater insight in the field.

An urgent call has been made for research that contributes towards the conceptual clarification of sustainability views and towards a better understanding of sustainability embeddedness in decision-making $[12,15,22,39,44,45]$. We argue that the realization of sustainability in practice and subsequent improved decision-making for enhanced sustainability can only be achieved when the current situation of sustainability embeddedness in decision-making has been conceptualized [33,55-57]. This requires in-depth involvement from practitioners and the necessary inclusion of subjective decision-making factors into interpretation such as ideology, values, norms, and context, due to their influence on an improved understanding of decision-making and strategy execution $[6,37,44,50]$. It is the aim of this study to respond to this call, thus revealing the principal gap and the purpose of this research.

To make sense of the sustainability embeddedness phenomenon in practice, and contribute to both theory development and improved sustainability performance, we adopt a problem solving approach to daily work and thinking, and ask questions such as "what is going on here?" [36,39,55,57]. We 
contribute to the persistent implementation gap by identifying and conceptualizing key antecedents of sustainability embeddedness in decision-making from which management can develop initiatives and programs. We offer "navigational support" to organizational leaders, management, and change agents by contributing to how sustainability is understood, embedded, and applied within decision-making at an organization. We also corroborated our findings with the existing literature on sustainability embeddedness. This served to strengthen the findings and test the applicability of theory in practice [58].

This study was guided by a primary research question: What are the key antecedents of sustainability embeddedness in decision-making? We engaged in a social collaborativesense-making - process with a diverse group of practitioners in a case company. Through individual and focus group interviews, we gathered rich data on the phenomenon. This was followed by the interpretation of responses, discourse, and actions around sustainability embeddedness in decision-making. Next, we made sense of the situation by constructing meaning around the key antecedents. These formed part of our contribution to a metaphoric "map" that navigates sustainability embeddedness in decision-making for practitioners as well as academics. We followed this with a management implications section that represents a "compass" that can be used to guide better decision-making towards improved sustainability.

\section{The Case Study and Context}

For this study, we found sufficient rationale for the use of a case study as part of a single case design strategy. The particular case company presented circumstances that supported the answering of the research question, the building of theory, and the providing of insight into the phenomenon [59]. It also offered a unique, information-orientated position that is discussed here for its potential value and influences on the findings [60-62].

The company chosen is a property company that develops, owns, manages, and refurbishes a large portfolio of industrial, retail, and commercial properties in a developing country. The case company is a leader in its industry, is listed on the Real Estate Investment Trust (REIT) in South Africa, and has developed a sustainable development strategy. This case company's leaders and managers are committed to embedding sustainability into business operations and to becoming a sustainable organization. For instance, the company has integrated sustainability into its strategic business planning and made a commitment to People, Planet, and Profit. The company strives to follow the Green Building Council of South Africa's standards for buildings, and has won numerous awards for reporting and for sustainable initiatives. Furthermore, this company formed part of another study that determined the status of sustainability embeddedness in strategizing [31]. A strategizing for sustainability index (SSI tool) was applied to the external and publicly available communication of the top 40 listed companies on the Johannesburg Stock Exchange, which included the case organization.

The analysis of evidence from this case study supported our goal to provide greater insight into sustainability embeddedness in decision-making, so as to improve the overall sustainability embeddedness of the property and other industries.

\section{Methodology and Data Collection}

After identifying the case company, we engaged with their top management, who provided permission for the study. Top management substantiated the prevailing management dilemma that was being investigated and the value of the research in practice. The case company's managers and leaders confirmed their commitment to becoming a sustainable organization but cited various challenges they had experienced with the current status of sustainability's embeddedness in decision-making. Top management expressed their need for clarification and a better understanding of the current status of sustainability embeddedness in decision-making in order to help them improve their decision-making and performance. In these initial engagements with top management, we also discussed the meaning of sustainability embeddedness [20]. This was the beginning of a social collaborative process between the 
researchers and practitioners in the study, and supported the establishment of a shared understanding of the phenomenon. We considered this step especially important given that there is an absence of clarity about how to define and conceptualize sustainability [12,15].

We collected data cross-sectionally over an eight-month period, but the groundwork and development of the study took more than two years. This period provided us time to analyze and interpret the data, enabling us to make sure that there was a match between our findings and the participants' reality [58]. In line with our pursuit of a better understanding of the sustainability embeddedness phenomenon, we chose to gather and interpret qualitative data from a diverse group of employees in the case company $[7,63]$. We engaged with the participants-the practitioners-from all management levels and areas of business using a purposive sampling technique. Research in the field of sustainability has mostly explored sustainability professionals or top management, thereby focusing on the views of particular management levels or divisions [33,39,56,64-67]. Practitioners in this study came from different functional and line divisions as well as from the different geographic regions from which the company operates. This decision was motivated by the knowledge that sustainability embeddedness is a diffusive process that should transpire across the whole organization $[8,20,68,69]$. Moreover, it is recognized that individual practitioners in middle and lower management levels play significant roles in promoting, mediating, negotiating, and implementing sustainability $[46,65,67,70]$.

The emphasis in this research was placed on the values of individual practitioners and their routines and practices that form part of decision-making and provide insight into strategizing and performance at an organizational level $[16,17,52,65]$. There is growing consensus that the engagement of individual practitioners contributes to a better understanding of sustainability issues and behavior, and to improved organizational adoption of sustainability $[22,37,44,46,67]$.

We conducted 15 voice-recorded individual interviews of $1.5 \mathrm{~h}$ each, using a semi-structured interview guide that we developed from literature on the subject. Thirty-six practitioners also participated in five focus group interviews with the same interview guide, except that questions were structured to suit a group setting. We were interested in both individual and shared conversations on the phenomenon. The interview questions sought rich qualitative data that we could use to make sense of sustainability embeddedness in decision-making [65]. We asked the participants about their understanding and opinion of sustainability, and about the making of sustainable decisions in practice $[7,71]$. We inquired about any challenges to making sustainable decisions $[57,67]$. Other questions elicited practitioners' descriptions of their perceived roles and responsibilities, as well as the primary daily and strategic decisions made in their jobs and the factors and criteria influencing those decisions [52,72]. It was important to identify how practitioners view themselves within their context, as it shapes their behavior and how they make decisions. By asking practitioners about the primary decisions made in their jobs, we sought to create retrospection, which was highly relevant to meaning construction. Our method also supported us to evaluate the implementation, operation, and management of sustainability embeddedness in decision-making [41,55,73].

\section{Data Analysis}

The analysis of case study evidence is one of the least established, yet vital, aspects of case study research [59]. As researchers, we acknowledge our role in the research and data analysis process and the influence of our values and beliefs on the construction of reality and interpretation of knowledge [63,74]. We have stated our epistemological and ontological assumptions here, along with our chosen paradigm for their influence on the findings. Our description contributes to rigor and to establishing the dependability and quality of the findings [59,61].

The researchers diverged to some extent on their assumptions. Researcher A attests that reality is constructed through interaction in the specific context, contributing to explanation building and the development of a working theory. Researcher B sees himself as an objective realist who believes that knowledge comes from facts associated with the case and the context. He believes that if repetitive conditions and patterns of sustainability embeddedness are found in decision-making, they can then 
be transferred to other cases. The researchers' divergent assumptions played a key role in contributing to the rigor and quality of the study [59]. The combined intellectual climate positively influenced the research methodology process and theory construction, adding strength and depth to the findings.

An interpretivist constructivist paradigm supported our objective to better understand the phenomenon from the studied actors in their social world [63]. We saw research as emerging from exchanges between participants and the researchers [75]. As interpretivists we were interested in the use of theory as a sensitizing device in our pursuit to construct meaning [63]. An open and inductive coding strategy was applied while using Atlas.ti software [74,76]. The process began with the reading of the transcribed responses of participants from the individual interviews. We then shifted our attention to the responses from focus group interviews, where we found support and confirmation for emerging findings $[63,75]$. Sense-making began with rough acts of categorization that led to the preliminary identification and mapping of ideas [57]. We considered the language from the interviews to be a reflection of practitioner views, values, and actions that enabled a greater understanding of how reality at the case company is constructed $[39,70]$. Interpretation of the evidence from both individual and focus group interviews assisted us with identifying patterns, relationships between constructs, and emerging themes. We continued doing this until no new themes developed and theoretical saturation was achieved $[59,61,63,74]$.

At the beginning, 22 general categories materialized, including "finance," "communication," "context," "risk," and "green technologies." However, as we familiarized ourselves with the data, we were able to merge categories and provide better descriptions of the emerging antecedents. As the data analysis process continued, we reduced the number of categories in Atlas.ti to 15. It was at this stage of engagement with the data that the metaphor emerged. Some of the initial antecedents were "Travel Fair and Tolls," "Red Tape," and "Deviations." We carved out their meanings and created conceptual labels for the purposes of interpretation [57]. From this process, we were able to reduce the antecedents used in the metaphor to six. We found that the Atlas.ti software allowed for more complex and detailed coding than manual thematic coding, which we suggest contributed to greater insight during the analytical process. During data analysis, we regularly engaged in reflective sessions where insights pertaining to the data and emerging findings were deliberated [58].

\section{Findings and Discussion: A Map}

Perrot [8] emphasizes that "before any planning takes place, management must understand the organization's current position on sustainability endeavors." In this section we aim to assist management to better understand the current status quo pertaining to sustainability's embeddedness in decision-making with the use of a metaphor.

There has been a call for the development of new metaphors in sustainability research for their ability to provide clarity on often complex concepts, offer a fresh perspective, and create meaning around realities and established perceptions $[46,77]$. Metaphors are important because they guide action by contributing to changes in our conceptual systems. This is especially true when the metaphors are grounded in experience-such as in this study-that directly or indirectly guides practitioners to a sustainable path $[77,78]$. Our aim is to use a navigation metaphor to describe key antecedents of sustainability embeddedness in decision-making. Antecedents are supported by direct quotes from the participants interviewed.

The proposed metaphor is explained using mapping terminology and draws on the common features that form part of navigation on a journey towards a destination. The metaphor is grounded in literature on sustainability, which has been conceptualized as a journey where practitioners are expected to navigate their way towards the desirable destination of becoming a sustainable organization $[8,15]$. The focus of this metaphor is to build and communicate a plausible map that gives meaning to the experiences, biases, and perceptions of practitioners on the journey [57]. The elements of the proposed metaphor and the antecedents are individually described and discussed in this section but are also tabulated for ease of reference in Table 1 . Table 1 contains each antecedent's label, the 
antecedent's description and supportive reasoning, and questions to guide management to identify the antecedents in their contexts.

Table 1. Outline of the proposed metaphor containing labels of antecedents used, a description of the antecedent, supportive reasoning, and guiding questions for management. Source: Own compilation.

\begin{tabular}{|c|c|c|c|}
\hline Antecedent & Antecedent Description & Supportive Reasoning & $\begin{array}{l}\text { Questions to Guide Management in to } \\
\text { Identify the Antecedents in their Contexts }\end{array}$ \\
\hline $\begin{array}{l}\text { A True } \\
\text { North } \\
\text { Destination }\end{array}$ & $\begin{array}{l}\text { Practitioner decisions are not } \\
\text { aligned with a True North } \\
\text { Destination of sustainability } \\
\text { embeddedness, which is leading } \\
\text { practitioners "off track" in their } \\
\text { decision-making. }\end{array}$ & $\begin{array}{l}\text { The vision and goal in } \\
\text { decision-making is particularly } \\
\text { influential to decision makers. } \\
\text { Sustainability-embedded } \\
\text { decision-making requires clarity on } \\
\text { the destination. }\end{array}$ & $\begin{array}{l}\text { Is our desired destination aligned with a } \\
\text { holistic, integrative, resilient view of } \\
\text { sustainability that supports the making of } \\
\text { sustainability-embedded decisions? Or does } \\
\text { it currently lead practitioners "off track" in } \\
\text { their decision-making? }\end{array}$ \\
\hline Mountains & $\begin{array}{l}\text { The three elements of sustainability } \\
\text { (financial, environmental, and social) } \\
\text { represent three Mountains } \\
\text { (obstacles) that should form part of } \\
\text { decision-making. Some elements are } \\
\text { considered more important than } \\
\text { others to practitioners. }\end{array}$ & $\begin{array}{l}\text { The three pillars or "cornerstones" } \\
\text { of sustainability should be } \\
\text { considered as interdependently and } \\
\text { integratively embedded in } \\
\text { decision-making. }\end{array}$ & $\begin{array}{l}\text { How do practitioners understand the three } \\
\text { elements of sustainability and the } \\
\text { relationships between them? Is there } \\
\text { evidence of patterns of prioritization in } \\
\text { practitioner decision-making in our } \\
\text { company? }\end{array}$ \\
\hline Fog & $\begin{array}{l}\text { Fuzziness, confusion, and } \\
\text { interpretation issues experienced by } \\
\text { decision makers that influence } \\
\text { sustainability embeddedness in } \\
\text { decision-making and practice. }\end{array}$ & $\begin{array}{l}\text { Sustainability is known to be a } \\
\text { complex concept. However, } \\
\text { confusion and uncertainty can result } \\
\text { in the continuation of } \\
\text { business-as-usual practices by } \\
\text { practitioners as opposed to } \\
\text { sustainability-embedded decisions. }\end{array}$ & $\begin{array}{l}\text { How is sustainability understood and } \\
\text { interpreted by practitioners at our company? } \\
\text { Do practitioners experience interpretation } \\
\text { issues, discrepancies, and confusion around } \\
\text { its meaning and operationalization? }\end{array}$ \\
\hline Myopia & $\begin{array}{l}\text { A limited and distorted view of } \\
\text { long-term sustainability that results } \\
\text { in shortsightedness associated with } \\
\text { three roadblocks. }\end{array}$ & $\begin{array}{l}\text { Short-termism as opposed to a } \\
\text { long-term view in the making of } \\
\text { sustainable decisions inhibits } \\
\text { sustainability embeddedness. }\end{array}$ & $\begin{array}{l}\text { Are practitioners able to see a long-term } \\
\text { view of sustainability clearly? Or are } \\
\text { practitioners constrained to a short-term } \\
\text { view when making decisions? }\end{array}$ \\
\hline $\begin{array}{l}\text { Navigation } \\
\text { Necessities }\end{array}$ & $\begin{array}{l}\text { Preparation and support are lacking } \\
\text { and desired by practitioners for } \\
\text { navigation of } \\
\text { sustainability-embedded decisions. }\end{array}$ & $\begin{array}{l}\text { The sustainability embeddedness } \\
\text { journey cannot be attempted } \\
\text { without support by management } \\
\text { and adequate resources and } \\
\text { knowledge to make decisions. }\end{array}$ & $\begin{array}{l}\text { Do practitioners feel equipped and able to } \\
\text { make sustainability-embedded decisions? } \\
\text { What additional support do practitioners } \\
\text { require from management? }\end{array}$ \\
\hline $\begin{array}{l}\text { The Chosen } \\
\text { Team }\end{array}$ & $\begin{array}{l}\text { Showing preference to a few "core" } \\
\text { stakeholders in decision-making. }\end{array}$ & $\begin{array}{l}\text { Sustainability-embedded decisions } \\
\text { should not favor or prioritize a few } \\
\text { stakeholders but instead incorporate } \\
\text { a wider group of stakeholders. }\end{array}$ & $\begin{array}{l}\text { Do practitioners see some stakeholders as } \\
\text { more important than others? Which } \\
\text { stakeholders appear to be more embedded in } \\
\text { decision-making than others? }\end{array}$ \\
\hline
\end{tabular}

\subsection{A True North Destination}

In order to become a sustainable organization, it is vitally important that practitioner decisions are aligned with a sustainable vision and that this vision is aligned with a True North Destination of sustainability embeddedness $[8,14]$. In this metaphor, a True North Destination guides the making of sustainability-embedded decisions and supports a shift in practitioner thinking and practices $[2,18]$. A True North Destination helps practitioners prioritize and manage the competing demands associated with making sustainability-embedded decisions in practice $[57,79]$.

Engagements with practitioners revealed a commitment to pursue sustainability and make it part of strategizing and decision-making. There was a broad consensus from practitioners interviewed that the company desires to be a "leader in sustainability" and to "be at the front end" by making sustainability part of "company strategy," "aligned with strategic objectives," and "strategic factors." Sustainability was said to form an "integral part of business" and was associated with "heading in the right direction" and the "sustainability of income streams." Practitioners shared convictions that sustainability was the "the right thing to do" and also spoke strongly of virtues such as "honesty and transparency." Practitioners corroborated recent literature by Ioppolo, et al. [80] when they shared these convictions and their desire to make an "ethical impact" by "driving good governance" and demonstrating "ethical and fair conduct." Practitioners also expressed a "keenness to outbid others" through the identification of "opportunities to grow," which included the making of "socially responsible" and "reputationally better ... green decisions." The destination appeared to include 
achieving both "growth and sustainability" and "sustainable growth in distribution." Practitioners saw sustainability as an "investment" that will have an "impact on the future of the business" and on the organization's "legacy and future." Sustainability was considered important for its ability to yield "steady growth in returns from green buildings and energy-saving" and to "sustain profit." Sustainability and greening efforts were believed to bring "complete and accurate visible results" and "financial and other rewards and opportunities" in the future. Ignoring sustainability was understood to have "negative consequences" that would be "felt down the road in terms of cost and survivability."

Although practitioners expressed a clear destination in terms of a sustainable strategy, strong values, and a vision to be sustainable, closer evaluation and interpretation suggest that the destination may be missing "True North". Our assertion is based on how practitioners used words such as "sustainability," "sustainable," and "sustain." These words mostly appeared before or after words like "income streams," "growth in distribution" and "profit." Practitioner understanding of sustainability appeared to be biased towards finances and indicative of confusion about sustainability's true-original-meaning $[8,15,29,81]$. We noticed that practitioners' sustainability focus remained on the financial bottom line as opposed to a triple bottom line. While economic growth is an essential part of sustainability, continuing along the paths of business-as-usual makes the destination of sustainability embeddedness impossible to reach $[15,29]$. Furthermore, a narrow focus on achieving economic growth limits the organizations' opportunities associated with sustainability innovation [10]. Practitioner discourse portrayed typical sentiments of strategic proactivity towards sustainability as opposed to embeddedness [20]. Discourse indicated that practitioners were struggling to make the necessary paradigmatic shift associated with sustainability embeddedness [5]. This led to our conclusion that decision-making is "off track" and not aligned with a True North Destination of sustainability embeddedness, which is the primary contribution of this antecedent. When practitioner decision-making is not aligned with a sustainability-embedded vision, it is likely to influence the organization's overall sustainability performance and transition to embeddedness [18].

\subsection{Mountains}

Mountains in this navigation metaphor represent the three elements of sustainability that should be embedded in decision-making for sustainability. Their prominence in terms of size and proximity to the practitioners results in some Mountains being considered more important, manageable, and embedded than others.

The first Mountain is the "Finance Mountain." It is considered very important and most manageable to practitioners-as alluded to earlier. Through engagements with practitioners, it was apparent that, for them, sustainability is predominately about the "financial situation." Conversations about practitioners' primary decisions and responsibilities in their jobs confirmed the importance of this Finance Mountain. Influences on practitioner decision-making include the "profit status of financials," "anticipated returns," "yields," "operating costs," and "arrears." Practitioners referred to "monetary value" and "monetary variance" as criteria influencing their decisions. Practitioners incorporated decision-making factors such as how the decision impacted on the "accounting of distributions" or how it contributed to a "return on investment." There was a shared sentiment that decision-making was about "driving [the] bottom line" and "financial sustainability." The embeddedness of finance measures in sustainability thinking was clear. This finding substantiated our earlier finding about the sustainability destination missing True North.

Due to the prominence of the Finance Mountain—financial and economic sustainability—it was revealed that the other Mountains; the "Green"—environmental sustainability—and "Social"—social sustainability-Mountains, are not considered as important or equally embedded in decision-making as the Finance Mountain [16,40]. The Green Mountain was said to be about "good initiatives" such as the "big energy drive," "energy saving lights," "green stuff," "green buildings," "fossil fuel and rhinos," and "renewables." Environmental sustainability was considered a means to enhance company reputation and to be socially responsible, and was not taken as seriously as the Finance Mountain. The 
Green Mountain came across as superficial in the sense that greening was predominately associated with short-term defensive and tactical efforts and having a good reputation [8]. Additionally, we noted that environmental and social efforts were seen to negatively influence traditional performance measures [16]. Environmental sustainability, i.e., Greening, was perceived to be costly, with an "absence of measurable benefits." Practitioners confirmed the prioritization of the Finance Mountain over the Green Mountain when they expressed that "sustainable green decisions are not necessarily sustainable financially" and highlighted that "sustainable initiatives require a capital investment" and the need for "green buildings to be rated so as to capitalize on the ratings."

References to "social sustainability" were relatively limited. Social sustainability was associated with "social responsibility," "caring about people and their families," "safety concerns," and achieving "work-life balance." For practitioners, social sustainability meant they needed to "combine properties and people," work with the "community," and be "caring about industry, the environment, our country." "Community" came across as a "catch-all" phrase for "other" stakeholders that were not a primary concern in practitioner decision-making. This was in accordance with literature that purports that the social dimensions of sustainability in general have not received the same prominence as the other two pillars $[23,26,82]$. This is made worse by the fact that the meaning and objectives of the social pillar of sustainability remain vague in practice [83].

The Finance Mountain overshadowed the positions of the Green and Social Mountains in practitioner decision-making. Consideration of environmental and social concerns by practitioners was said to be "dependent on the budget" and on the "daily cash requirement." Before social and environmental elements of sustainability could be considered, practitioners needed to first review the "bank statements as inputs" and ask "do we have a budget?" Understanding that this reality influences the making of sustainability-embedded decisions, some practitioners were able to summarize the issue. They referred to the issue as a "budget mentality" and emphasized that "decisions are often budget driven," resulting in an outcome "that may not be as sustainable as conceivable." It became evident that the Green and Social Mountains were only considered manageable and part of decision-making when it was financially beneficial to do so. Practitioner decision-making focused on the intersection between the elements of sustainability, which they referred to as "win-win situations for everyone." As such, we noted a strong preference towards an instrumental, business-case view of sustainability as opposed to an integrative view [15,45]. We noted that practitioners established a hierarchy and prioritization in their decision-making, where financial outcomes at the organization take precedence over other sustainability concerns [7,29].

We see this antecedent as offering a few specific contributions. Firstly, each "cornerstone" of sustainability has been conceptualized and its embeddedness in decision-making has been made clearer. In order to build a sustainable organization and improve sustainability embeddedness in decision-making, a better understanding of each element of sustainability is needed $[8,20]$. Secondly, the Mountains antecedent provides insight into the potential relationships between the elements of sustainability and their influence on sustainability-embedded decision-making. Lastly, and very importantly, this antecedent highlighted the current patterns of prioritization existent in practitioner decision-making. It draws management's attention to the social and environmental elements of sustainability that are currently neglected in practitioner decision-making. Unless decision-making for sustainability integratively and interdependently considers each element important, decision-making outcomes will continue to be aligned to goals of profit maximization, as opposed to the long-term resilient "end goal" associated with sustainability embeddedness [20,28,45].

\subsection{Fog}

The Fog antecedent represents the managerial and contextual uncertainty, ambiguity, and intangibility experienced by practitioners when making sustainability-embedded decisions. Fog is a descriptive label that refers to practitioner difficulty experienced in gaining clarity and understanding around sustainability in practice $[42,43,46]$. Fog appears to be influencing sustainability embeddedness 
in decision-making by side-tracking practitioners (the navigators) from embeddedness and the goal of sustainable development.

Reference was made by practitioners to "interpretation issues," "fragmented information," "complexity," and the need to "filter requirements with discernment." The making of sustainable decisions was complicated by challenges in "conceptualizing strategy" and existent "discrepancies" in information pertaining to sustainability. Practitioners emphasized that while their understanding was "dependent on ... two way communication," there was currently a "lack of communication" and a "lack of internal consultation." This was believed to be contributing to practitioner confusion about sustainability embeddedness, i.e., Fog. Practitioners shared that "other people's strategies are unknown" to them and that there is an absence of complete knowledge when it comes to sustainability $[45,80]$. Sustainability was confirmed to be a "misunderstood phrase" and in general there was a "lack of understanding and miscommunication" around the concept that contributed to their interpretation issues. Some practitioners shared doubt that "the business or other people understand [sustainability]." Fog or fuzziness in the decision-making process appeared to emerge from the absence of effective communication and strategy discourse around sustainability [16,42]. Consequently, we saw a connection between Fog and practitioner confusion experienced in the first antecedent (A True North Destination).

Findings also highlighted discrepancies and confusion about the responsibility of sustainability, which appeared to be affecting the embeddedness of sustainability in their decisions. Practitioners shared their uncertainty (Fog) about whether sustainability was really supposed to be an embedded part of their individual decision-making in their jobs or whether it was the responsibility of the sustainability department $[10,16,18,84]$. Some practitioners expressed that "staff look at sustainability" and that it formed "part of projects or development"; however, others shared the view that sustainability was not part of their job, but the responsibility of the "utility and sustainability department." These practitioners shared a belief that they "don't work with things [i.e., sustainability] like that" and that sustainability "does not resonate in my job." Through continued engagement, we understood that "some people adhere [to sustainability] but others don't," that "not everyone follows the same protocol," and that people are not "always aware of sustainability initiatives" but rather "everyone does their own thing" when it comes to sustainability. Practitioners revealed that they were confused when it came to the responsibility for sustainable decisions and initiatives. It emerged that these discrepancies could be a result of the current "disconnectedness in departments" that contributed to their confusion. Practitioners described the issue as a "silo mentality" that meant "everything" (including sustainability) was "broken into silos." This appeared to be exacerbated by the fact that there was currently "no link between performance and rewards" and that "no rewards are linked to operating in a sustainable way." It emerged that a connection between practitioners' sustainability-embedded decisions, responsibilities, and rewards was absent, which contributed to confusion.

Interpretation of the Fog antecedent, other antecedents in the study, and related literature suggests the existence of subcultures within the organization and the absence of a shared culture that supports the making of sustainability-embedded decisions $[16,20,22]$. Subcultures refer to groups of individuals within a company who hold different beliefs pertaining to sustainability $[10,16]$. Their beliefs are not always aligned with each other or to the goals of sustainability embeddedness-as revealed in this antecedent. Subculture attitudes hamper the diffusion of a unified sustainability embedded culture that shares common values and beliefs pertaining to sustainability $[10,14,22]$. Findings correspond with signs that point to the existence of subcultures, which is problematic for embeddedness $[20,84]$. Some of these signs were practitioner beliefs about corporate goals and practices being based on external forces such as the importance of company "reputation" and "industry objectives" (see a True North Destination and Myopia). Additionally, practitioners revealed that they currently prioritize and maximize economic gains such as "income streams" (see Mountains). We also found evidence of instructional communication from top management and centralized decision-making, which is also indicative of subcultures hindering embeddedness. Practitioners shared that they required "authorization by 
management" before making decisions (see Navigation Necessities). Decision-making also emerged as being market-based, in that practitioners relied on "benchmarking" and "external factor analyses" (see Myopia). Findings also pointed to the manifestations of change or responsibility for sustainability in some departments and not in others-which we discussed in this Fog antecedent $[10,16,26]$.

Overall, Fog pointed to the existence of conflicting opinions around sustainability in practice, intra-organizational differences in how employees understand, interpret, and operationalize sustainability, and varying levels of awareness of sustainability information, initiatives, and practices $[15,26,39,85]$. Practitioners in the study experienced "fuzziness" and struggled to deal with many complexities and ambiguities associated with the making of sustainable decisions [42,43]. Fog is an important finding because when foggy and complex situations are not identified and managed, practitioners tend to use them as justification for the continuation of a business-as-usual approach [16,29]. Practitioner confusion about sustainability and its meaning can also result in practitioners continuing to place greater emphasis on financial sustainability as opposed to considering all the elements together [22]. In addition to the identification and conceptualization of Fog, we also provided an explanation for Fog's existence and its influence on sustainability embeddedness in decision-making, by drawing on direct quotes and findings in the study and related literature [16]. Thus, the value in this finding is the identification, conceptualization, and explanation of Fog-which we see as contributing towards management's better understanding and navigation of the phenomenon.

\subsection{Myopia}

Myopia in this metaphor represents a limited-shortsighted-and distorted approach to the making of sustainability-embedded decisions. In this metaphor, it is as if practitioners can see objects that are familiar and in close proximity clearly, but objects further away are blurred. In managing and balancing the shift from short- to long-term considerations of sustainability in decision-making, practitioners experienced challenges, revealing Myopia [14,16,69].

Practitioners described their situation by saying that there is a "short-term view currently" and that their "short-term thinking doesn't consider the future." Practitioners expressed a "lack of a long-term view," which was described as "a barrier" to sustainability embeddedness in practice. Practitioners shared that they struggled to balance the "short-term, versus long-term focus" in decision-making. When practitioners looked through a metaphorical telescope they could see a long-term picture associated with sustainability (A True North Destination), yet struggled to align their decisions with it. Practitioners understood that sustainable decision-making meant they should not be "looking for short-term gain" but rather focus on the "long term" without making "short-term compromises on good quality." They agreed that they needed to make "decisions that stand the test of time" with "longevity" in mind and for "effectiveness in the long term." This meant they needed to maintain a commitment to "the long haul ... and to the big picture." It became clear that practitioners were struggling to balance the tension between a short- and long-term view associated with sustainability-embedded decision-making [42]. Further engagement with practitioners led to a clearer understanding of this antecedent, its connections to other antecedents in the study, and to the emergence of three roadblocks contributing to Myopia. These Myopia roadblocks are listed here and explained below: (1) month-end mentality, (2) climate conditions, and (3) known paths.

Firstly, practitioners struggled to make "choices between long- and short-term solutions to a particular situation or problem" because they faced many urgent demands and requirements. Practitioner decision-making was challenged by what they referred to as "month-end" and "year-end mentality." Month-end mentality meant that decision-making focused on dealing with the current short-term "requests or enquiries" and "issues" and "disputes" as opposed to making long-term sustainable decisions. As a result, practitioners "prioritized" certain issues in their decision-making by considering the "frequency and urgency of topic," the "urgency to obtain income," and "business demands." Practitioner decision-making was influenced by "due diligence, "compliance with rules," 
"risk prevention," and "reporting requirements." Practitioners' ability to see and act in accordance with a long-term sustainable goal appeared to be constrained by the current policy, procedures, and business practices. Urgent demands associated with certain stakeholders and the month- and year-end reporting of results caused practitioners to ask themselves questions such as "what is the best solution now?" and "what is expected of me now?" This roadblock in decision-making was summarized when one practitioner stated "decision-making is based on current circumstances that present themselves."

Secondly, we determined that Myopia (short-sightedness) was also influenced by reactive responses to the external environment (the climate conditions). Practitioners followed practices such as "trend analyses," "benchmarking," and "external factor analyses." They also responded to themes and trends in the industry by reviewing "market data," "market related rentals," "industry objectives," and "industry demands." Practitioners referred to these as "external influences" and "economic conditions" affecting their ability to make long-term sustainability-embedded decisions. Practitioner decision-making for sustainability appears to be strongly affected by what the industry is doing and how the industry affects their business, as opposed to doing what is right and what is sustainable. When testing this finding against the literature, we determined that practitioner adherence to industry norms in their response to sustainability may be indicative of an industry macro-culture affecting sustainability embeddedness [16].

Thirdly, we found that practitioner decision-making followed metaphoric "known paths". This was due to uncertainty and insecurity about what lay in the future and, as such, we were able to see a connection between this finding and the Fog antecedent. A known—or desired-path is the shortest, most easily navigated route between the origin and the destination. Known paths, also referred to as "shortcuts," are often off limits and can be damaging to the environment [86]. In this case, known paths obscure the long-term vision of sustainable development, exacerbating a myopic view. Practitioners shared that "predicting the future is tricky" and that there was a "fear of new ideas." As such, they saw and took shorter known paths in their decision-making because these paths represented "what worked" in the past and yielded financial performance. Practitioners knew it was easier to make decisions that are aligned with an "existing comfortable fit" and draw on "proven track records" and "prior specialist work done." Practitioner decision-making was influenced by "similarities between similar problems in the past." It was recognized that practitioners would continue along known paths as long as they "keep doing what you're doing without a serious impact on the future of the business."

In addition to demonstrating the existence of a myopic view of sustainability in decision-making, the Myopia antecedent provided further and better understanding of other antecedents in the study. For instance, the Myopia antecedent (a limited and distorted view of sustainability) provides insight into why practitioners are not seeing a True North Destination of sustainability. Myopia also explains why practitioners can clearly see the prominent Finance Mountain, but the Social and Environmental Mountains appear to be outside of their sight range. Findings in this Myopia antecedent also confirmed practitioner interest in repeating decisions that yielded financial performance (see Mountains). It also became clearer in this Myopia antecedent that when practitioners struggle to see the long-term view of sustainability in practice, they will also struggle to understand sustainability and its applicability to their jobs (Fog). Managerial preference for known paths found in this antecedent, as opposed to abstract understandings of sustainability, can be expected when there is confusion in practice (Fog) [16]. Shortsightedness also explains why practitioners focus on short-cuts and known paths in the form of $a$ d hoc greening initiatives that are not always focused on long-term performance (see Mountains). Myopia was found to impact the business in terms of resilience and long-term performance and will continue to impede the realization of sustainability embeddedness in decision-making unless it is addressed.

\subsection{Navigation Necessities}

Being equipped for any journey is crucial to one's ability to reach the desired destination. Similarly, the sustainability embeddedness journey requires preparation and support in terms of training and 
knowledge transfer, decision-making authority, and also resources for the journey. In this antecedent we refer to these as the Navigation Necessities required for the enhancement of embeddedness in decision-making.

Practitioners emphasized the need for increased training and knowledge transfer of sustainability, which is known to have a positive effect on sustainability embeddedness $[10,46,85,87]$. Practitioners highlighted that sustainable decision-making requires unique abilities such as "problem solving abilities for long-term solutions." References were made to the importance of "knowledge," "available expertise," "education and understanding," "attitude and aptitude," and access to both "internal knowledge" and "suitable qualified suppliers with appropriate skill sets to resolve problems." In actuality, practitioners felt there was currently a "lack of skill" and a "lack of competence." Practitioners referred to the "lack of know-how ... being a key issue" in the making of sustainability-embedded decisions. Practitioners shared that they needed management to "pass on skills and abilities to subordinates," to "do more training," and also to provide "mentoring, training, and guidance." They considered this to be crucial to the making of better, more embedded decisions for sustainability.

There was agreement amongst practitioners that sustainability embeddedness not only required competencies but also the decision-making authority to navigate and make sustainability-embedded decisions. It became apparent that practitioners were not granted enough authority, and as a result their ability to make sustainability-embedded decisions was affected. Practitioners referred to the need to gain "authorization by management" before making primary daily and strategic decisions in their jobs. They also referred to the need to "get approval," acquire "leadership influence," and, in some cases, "direct instruction" for the making of decisions. Business decisions and sustainability issues needed to be brought to the "CEO's attention" and were subject to "getting it approved internally with stakeholders." It is recognized that managers can pose some of the most formidable obstacles to a sustainability-embedded culture change $[16,19]$. Manager-centered decision-making, as opposed to consensual and devolved decision-making, is known to influence the embeddedness of sustainability in practice [10,14]. Practitioners confirmed this by sharing that "authority levels hampered" the embeddedness of sustainability in decision-making, and shared a desire for "enough direction and room ... and support to get it done." Practitioner decision-making authority was affected by the fact that the "decision-making ability is always at higher levels" and often "beyond our authority." We assert that this could be another possible explanation for why practitioners are confused about the responsibility for sustainability (see Fog).

In addition to these Navigation Necessities, practitioners desired more from the "pool of available resources" for improved navigation and enhanced sustainability embeddedness. It is known that increased resources facilitate practitioners' adoption of sustainability principles $[10,16]$. Practitioners in this study confirmed this and called for an increase in the "availability of materials," including "research facilities in-house," better "access to capital," more "capacity in hours," and "green technologies." Practitioners perceived the current shortage of resources, time pressures, and "poor technology to support long-term decision-making" as affecting the making of sustainability-embedded decisions [42].

The value of this Navigation Necessities antecedent arises from the combined knowledge of what practitioners believe is lacking and what is considered necessary for the making of improved sustainability-embedded decisions. The insight in this antecedent-gained from practice and supported by the literature - can be used by management to support practitioners' improved sustainability embeddedness in decision-making. Additionally, we were able to draw connections to our earlier findings which served to substantiate and better understand them.

\subsection{The Chosen Team}

The Chosen Team represents a group of stakeholders selected by practitioners who form an important part of the sustainability journey. The Chosen Team revealed itself as a key antecedent 
in the study. While practitioners did not openly acknowledge the existence of a specific group of stakeholders, it emerged as a normative justification for practice and decision-making. Practitioners demonstrated that they communicated and engaged the most with customers (tenants), employees, and the providers of capital who formed part of their "team" on their navigation journey.

Practitioners' daily practices and decision-making orientated around "engagements ... with people," "working with people and getting the best out of people," and also "balancing control and service" and "balancing requests." Decision-making practices included consideration of people's needs and demands. It soon became evident, however, that practitioners were referring to the needs of a few key stakeholders and that the goal was "building relationships for smoother running" with them. Practitioners shared that it is essential in practice to have good "tenant relationships" and to "visit tenants" and to assess "tenants' requirements." References were also made to "tenant communication" and incorporating "tenant feedback." Tenants and meeting their needs formed part of practitioners' daily and strategic decision-making, along with employees (co-workers). Practitioner decision-making was also influenced by the need to "consult another facilities manager" and incorporate "internal departmental messages." Practitioners expressed a need to be "conversant in building management" and to "reinforce the internal conversation" and internal "feedback" processes. The other important members of the Chosen Team were the contributors of capital or project influencers. Reference was made to incorporating the "responses of contributors" into decision-making and the "expectations from project stakeholders" as well as delivering on "shareholder interests."

Stakeholders appeared to be chosen by practitioners for the extent to which their demands required immediate or urgent attention and for their influence on the present operational and financial needs of the company [7,29]. As such, the Chosen Team represented those who influenced the short-term survivability of the organization, material gain, and organizational risk $[16,26]$. Subsequently we noticed connections between this antecedent and the month-end mentality roadblock described in the Myopia antecedent and to the Finance Mountain antecedent. Our findings suggest the existence of a prevailing business philosophy and decision-making practice promoting certain stakeholders and short-termism $[16,45]$.

Stakeholder management and prioritization practices significantly influence decision-making and the sustainability agenda [26,29]. When stakeholder management practices are based on an economic model or philosophy, such as in this case, it is known to impede sustainability embeddedness in decision-making [15,29]. The Chosen Team antecedent confirmed our concern that sustainability embeddedness may not be aligned with True North in practice. It also indicated that sustainability was currently more aligned to an instrumental view [23]. This antecedent offers value in knowing who are currently considered "stakeholders" when making decisions, and, indirectly, those who are being left out $[18,26]$. It also provides a foundation for reviewing current stakeholder prioritization practices so as to ensure that a broader group of stakeholder interests are incorporated into decision-making in the future $[7,14]$.

\section{Management Guidance and Implications for Practice: A Compass}

Effective navigation requires the use of both a map and a compass. In the previous section we "mapped out" the key antecedents of sustainability embeddedness in decision-making, which is the primary contribution of this study. We conceptualized each antecedent, proposed relationships and connections between them, and confirmed them using related literature. In this section we provide management with a compass, by offering guidance and practical advice in response to each antecedent, so as to support management in developing initiatives that improve sustainability embeddedness in decision-making. Additionally, we offer various questions that assist managers to identify the antecedents in their context. These questions are contained in Table 1. We recommend that they be used conjunctively with the guidance offered in this section.

The Truth North Destination antecedent emphasized practitioners' strong commitment to sustainability values, virtues, and beliefs. Practitioners articulated that sustainability was the right 
thing to do, which is considered an important prerequisite for embeddedness [14,16,44]. However, it was demonstrated that the existence of a strong commitment and vision for sustainability does not necessarily mean that practitioners have a higher understanding of sustainability embeddedness, or that their pursuit is aligned with the correct destination $[15,16,48]$. It emerged that practitioners were saying the "right" things about the importance of sustainability, but remained misguided ("off track") and confused about sustainability's meaning or how it should be embedded in their decision-making and practices. The True North antecedent emphasized the absence of a fundamental shift in practitioner decision-making, from seeking to diminish the organizations' negative impacts, to understanding how their decision-making can create a significant positive impact in critical and relevant areas for society and the planet $[20,22,40]$. We suggest that management review the organizational vision to ensure that it is aligned with a holistic and integrative view of sustainability and that it is widely understood [7,79]. This will assist practitioners in making sustainable decisions that are aligned with resilience and long-term performance as opposed to only focusing on short-term economic survivability [8].

The Mountains antecedent provided a better understanding of how each element of sustainability is perceived in practice, in addition to demonstrating the relationships between the elements. The Mountains antecedent confirmed our concerns discussed in a True North Destination antecedent about the prioritization of the financial element of sustainability in decision-making. In relation to the Finance Mountain, the Social and Environmental Mountains took a far less prominent position in practitioner decision-making. Social and environmental sustainability initiatives were described as "good" and "caring" but appeared separate and superficial because they were reflected as costly efforts to enhance reputation and be seen as socially responsible. The Mountain antecedent demonstrated the ideology and beliefs of practitioners that emphasized the financial and operational importance of the business, as opposed to a resilient, sustainability-embedded strategy for the long term. Practitioners referred to the "budget mentality" barrier that influenced the embeddedness of social and environmental sustainability in decision-making. To address this, management needs to stress that the most sustainable decision is not necessarily one that is affordable and that practitioners should pursue integrative decisions that address all the elements of sustainability [20]. Additionally, practitioners should not be blamed or punished for not meeting short-term financial goals when they have made a sustainable choice [42]. This calls for a change in management processes and the alignment of rewards with sustainable behavior [6,79]. Sustainability in strategy discourse also needs to be associated with the simultaneous inclusion of all three elements. This will assist practitioners with looking more holistically and integratively at sustainability when making decisions [22].

The Fog antecedent confirmed the confusion and complexity that surround sustainability in practice. It highlighted that practitioners struggle to understand and interpret sustainability and its operationalization. Practitioners experienced fragmented communication and felt separate from sustainability-related work and practices. This led to discrepancies and uncertainty that we suggest proves the existence of subcultures and an absence of a single, unified, sustainability-embedded culture [20,22]. To address this antecedent, top management need to consider a revised vision and leadership philosophy that is aligned to more integrative sustainability values and beliefs $[10,14]$. The sustainability-embedded vision should be widely disseminated through sustainable leadership practices and leadership's strategy message [16,22]. The effective diffusion of knowledge about sustainability and the framing of sustainability issues for practitioners are important for sustainability embeddedness and for the fostering of a shared culture $[42,44,46,88]$. To encourage desired sustainable behavior, management should ensure that environmental and social indicators are incorporated into employee evaluations and that the organizational structure supporting embeddedness is freed of barriers [89]. Sustainability embeddedness relies on practitioners seeing their jobs as interdependent and interconnected with sustainability, which is not only the responsibility of a sustainability department [20,84]. Additionally, performance in general should be measured by long- and not short-term profit and growth. These efforts are known to impact the embeddedness of sustainability in 
practitioner decision-making by assisting practitioners to feel connected to sustainability in their jobs and minimize the Fog experienced [10,14,79].

The Myopia antecedent highlighted that practitioners struggled to see and manage the shift from short- to long-term considerations of sustainability in decision-making. Myopia also served to give further meaning to, and better understanding of, other antecedents in the study, including the Mountains, Fog, and the Chosen Team. Practitioner Myopia (shortsightedness) in decision-making was found to be associated with three roadblocks that prevented practitioners from seeing and responding according to a long-term, integrative view of sustainability. These included month-end mentality, climate conditions, and known paths.

The month-end mentality roadblock represented the attention given by practitioners to urgent issues and demands. This finding was in accordance with Harris and Crane [16], who also found that practitioners focused on dominant issues including survivability, profitability, and other pressing concerns as opposed to having a long-term focus. In order to help practitioners overcome this month-end mentality roadblock, managers should consider framing environmental and social issues as being equally as urgent as financial issues. This involves conveying to decision makers that the issue warrants immediate attention and requires their response [46]. Furthermore, managers can reinforce desired behavior by redesigning policies to embody the principles of economic, social, and environmental sustainability $[16,66]$. For instance, Paul Polman, CEO of Unilever, stopped quarterly reporting because it encouraged short-termism and shareholder-centric behavior in employee decision-making [14,90]. Embedded and supportive sustainability policies have been found to be an important aspect in shaping how organizational actors understand and embed sustainability in decision-making [10].

The climate conditions roadblock represents practitioners' external focus. Climate conditions cause practitioners to be market-driven in their decision-making, in response to trends and industry demands. While these are important considerations in strategizing, sustainability-embedded decisions should not be dictated by the market and industry [22,79]. Attention should instead be focused on making long-term resilient choices that are best suited to the organization's own sustainability journey. To support practitioners in making sustainable decisions, management needs to map out a clear path towards sustainable development goals that are customized to the company. This can be used to guide decision-making and is particularly important in tough economic times, when practitioners tend to follow the industry trends [8,19]. It is important that practitioners realize that leadership often means navigating one's own path as opposed to following the paths of others. This framing of sustainability is likely to support practitioners with making sustainability-embedded decisions in practice $[46,57,79]$.

The known paths roadblock signifies the taking of the shortest, easiest path in decision-making. Practitioners took "shortcuts" as opposed to choosing the long-term sustainable path in their decision-making. This is because practitioners feared the unknown future, held on to their knowledge of what worked in the past, and felt comfortable with existing practices. When practitioners chose to take the shortest routes known to them in their decision-making, it became clear that their preference was for business-as-usual. To address this, management needs to encourage and allow practitioners to try out new green suppliers or technologies and provide the necessary decision-making support to help them make a sustainable choice. Furthermore, knowledge of practitioner tendencies towards known paths should be incorporated into change-management processes so as to transition individuals' thinking, behavior, and decision-making away from business-as-usual and towards different ways of operating, in line with embedded sustainability values [14,15,91].

Navigation Necessities represents the preparation and support that practitioners believe are currently lacking in practice. Engagements with practitioners revealed a desire for three Navigation Necessities from management that would contribute to enhanced sustainability embeddedness in decision-making. These are training and knowledge transfer, decision-making authority, and resources.

Practitioners indicated that more training and knowledge transfer from top management is required for the making of sustainability-embedded decisions. Sustainability-focused training 
initiatives are known to contribute to company-wide learning and a better understanding of sustainability $[10,13,85,87]$. Management can support practitioners by providing additional training that is collaborative and inclusive of practitioners in all functions. Additional sustainability-focused training offers many benefits, including raising awareness about the importance of sustainability as part of decision-making, attributing to increased capabilities for the making of improved sustainability-embedded decisions, and assisting practitioners to see sustainability as part of everyone's job, thereby contributing to increased commitment $[79,85]$. Practitioners also shared that there was an absence of decision-making authority when making decisions, which hindered sustainability embeddedness. It is important that management allows practitioners to coordinate strategies and make decisions from the three main streams of sustainability $[8,14]$. To enhance sustainability embeddedness, management could revisit practitioner decision-making authority and ensure that it is decentralized and includes practitioners on all levels $[14,16]$.

While it is important that management provide practitioners with sufficient resources to make sustainability-embedded decisions, it is also important for management to first consider which cognitive frame practitioners come from. According to Hahn et al. [42], a greater availability of resources will not necessarily result in practitioners considering and exploring broader sustainability issues if they do not already do so in practice. Increased time and resources can facilitate the search for more information in order to make improved sustainability-embedded decisions, but only if practitioners have the correct cognitive frame prior to the search. When the sustainable vision is "off track" (see a True North Destination) and practitioners hold an institutional or business case cognitive frame (see the Finance Mountain) and resources are given, then practitioners will continue to direct them towards the economic aspects of decisions. It is therefore important for management to first focus on transforming practitioner beliefs and values about sustainability towards an integrative view before allocating resources $[2,7,22]$.

The Chosen Team antecedent is significant because it supported and confirmed the emerging themes in the study, in addition to providing interesting findings of its own. The Chosen Team distinguishes a group of stakeholders that are considered "core" or "primary" among practitioners. Practitioners did not openly acknowledge practices of selection or prioritization, but analysis of their discourse revealed otherwise. Practitioners focused on the needs, demands, and requirements of the Chosen Team, which consisted of customers (tenants), employees, and the providers of capital. The Chosen Team appeared to be chosen for their urgent demands placed on practitioners, degree of influence, and contribution to material gain and economic survivability [16,26].

Practitioners revealed a dominant philosophy and orientation towards the Chosen Team of stakeholders, as opposed to including a wider group of stakeholders in decision-making [14,23]. This practice poses challenges to the sustainability agenda for a few reasons: Firstly, when practitioners select stakeholders using economic criteria, they will continue to give precedence to financial sustainability (see Mountains) in decision-making-even to the detriment of long-term resilience. Secondly, practitioners are unlikely to change their beliefs and thinking from business-as-usual while continuing to favor shareholder interests $[15,29]$. Thirdly, the choice of the Chosen Team could result in the exclusion of "discretionary" stakeholders that could result in fewer resources for them, as well as lost opportunities to operate sustainably as an organization [10,26,42]. To address this Chosen Team antecedent, management needs to revisit current sustainability and stakeholder management strategies and prevailing philosophies [16,29]. In particular, the association of sustainability with "sustainable growth" or "sustainable income streams" that regularly emerged in the study needs conversation and attention. We suggest that this misguided thinking may have led practitioners to believe that focusing on the Chosen Team is in effect delivering on the organization's current strategy and destination. Additionally, leadership is encouraged to emphasize to practitioners that everyone matters to the organization and promote the inclusion of a broader group of stakeholders in organizational goals and objectives $[7,14,15]$. Stakeholder engagement and management should also form part of the training programs referred to earlier [79]. These should communicate that stakeholders 
should not only be measured on their influence on the economic survivability of the organization, but rather on the long-term resilience and performance of the organization [79].

The antecedents presented in the metaphor emphasize that the journey to sustainability embeddedness remains challenging, complex, and not clear-cut for those in practice. However, the findings and this discussion offer management both a map and a compass with which to develop initiatives and programs for how to improve.

\section{Contribution and Concluding Thoughts}

Sustainability embeddedness is not for the faint-hearted. This study confirmed this and offers six conceptualized antecedents that emerged from the tangible real-life struggles and experiences of practitioners. These are a True North Destination, Mountains, Fog, Myopia, Navigation Necessities, and the Chosen Team. The study provided a representation of the current reality pertaining to sustainability embeddedness in decision-making so as to provide a platform for management to intervene and improve the status quo. This study responded to a resilient gap between actual and desired levels of sustainability embeddedness in decision-making, and forms part of a relatively smaller field of corporate sustainability studies taking an integrative view of sustainability embeddedness $[2,7,8,20,23,45]$.

We determined that other studies in the field, while valuable and related, did not focus specifically on the antecedents of sustainability embeddedness in decision-making or conceptualize them in a metaphor and nor did they intend to. This study offers new insight, unique descriptive labels, and valuable findings that emerged from the in-depth involvement of those in practice. As part of this study's contribution and sense-making process, we also proposed relationships between the antecedents that enriched our understanding of their existence in practice. Our decision to incorporate the literature into our discussions served to test the theory and its application in practice, and contributed to enhanced interpretations of the antecedents. We assert that the proposed metaphor and antecedents offer a better understanding of a complex phenomenon, support to management, and a contribution towards theory development.

The study's findings emphasize the importance of management's attention to a clear shared vision of sustainability embeddedness that influences the cognitive thinking, decision-making, and behavior of practitioners; the conveying of the vision by leadership; and the importance of aligning sustainability beliefs and values with supportive structures, policies, and performance measures. The study also highlights the need for top management to relook at training efforts and the amount of authority and resources given to practitioners for the fulfillment of the vision; and calls for an adjustment of current stakeholder engagement and management practices. Most noticeably, the study reiterates the importance of organizational change for sustainability so as to create a shared culture of embeddedness. We suggest that this can be achieved by management over a period of time through the dismantling of existing frames of reference (e.g.: budget mentality, silo mentality, and month-end mentality) and by incorporating the antecedents into change management endeavors $[16,19,20]$.

More broadly, this study accentuates the vital role that regulatory agencies have in the development of sustainable development policy-making and their role in creating legitimacy for organizations that are working towards sustainability embeddedness. Market, regulatory, and external pressures are considered drivers in embedding sustainability in organizations and in bringing attention towards sustainability embeddedness in practice $[16,22,66]$. The embeddedness of sustainability in decision-making was found to be influenced by current external market practices that formed part of decision-making (climate conditions). As such, changes and improvements to regulation are likely to positively impact on the making of sustainable decisions. This is particularly true for organizations that are currently still focused on the economic aspects of decisions $[7,8,22]$.

Even though the antecedents emerged from a single case and appeals for organizational change in the property industry, we believe that findings are transferable and that managers in other contexts are able to relate to and benefit from them. The proposed metaphor and antecedents can be used 
by managers as a sense-making device or framework to navigate their way through the realities pertaining to sustainability embeddedness in decision-making. We recommend that managers consider all antecedents simultaneously, owing to their inter-relatedness; however, individually they also offer insight and support for management. The metaphor and proposed questions contained in Table 1 can also be used to start important conversations among practitioners so as to develop strategies for improved sustainability embeddedness and performance.

Our methodological choices offered value and formed part of our overall contribution. We purposely incorporated the subjective views and ideologies of a diverse group of practitioners in the case company. The range of beliefs and ideologies that emerged enriched our approach and the quality of the findings. We also were able to establish a widely shared understanding of sustainability embeddedness in decision-making, as opposed to that of a single management level or department [16,39]. Notwithstanding the value of our approach, the methodology has limitations that should be considered when interpreting the findings. At the beginning of our research, there were no antecedents or metaphors. During the data collection phase, numerous labels and metaphors were developed and discarded; those remaining were frequently modified to take into account new insights. The proposed metaphor was developed from the conceptualization of the findings by the researchers, who have their own biases as well as experiences that could have influenced the results. Furthermore, the antecedents emerged from a process of grouping related findings in order to improve understanding. This could have resulted in the exclusion of other findings, although this was not our intention. In spite of the fact that the study also has limitations in terms of its generalizability of findings from a single case study, it highlights the restrictions of an institutional view of sustainable development that are likely to be applicable to other organizations. The findings demonstrated that when financial sustainability is the primary focus of sustainability strategies and decision-making, organizations will continue to adhere to their traditional business models and familiar methods of addressing sustainability issues.

Future research could investigate the antecedents—individually or collectively-in other contexts and investigate the relationships between them. The inter-connectedness between different antecedents is implied is this study, and further research into each could form part of future research.

The aim of this study was to provide "navigational support" to management at the case company and contribute to a better understanding of the sustainability embeddedness phenomenon for other companies too. We believe this was achieved through the contribution of the antecedents and that they contribute to improved sustainability performance in practice by providing organizational leaders with a platform from which to begin strategic conversation and to develop strategies.

Acknowledgments: We thank the case company for permitting and supporting this research.

Author Contributions: Both researchers contributed equally to this research.

Conflicts of Interest: The authors declare no conflict of interest.

\section{References}

1. Porter, M.E.; Hill, G.; Pfitzer, M.; Patscheke, S.; Hawkins, E. Measuring Shared Value: How to Unlock Value by Linking Social and Business Results. Available online: http://www.fsg.org/publications/measuringshared-value (accessed on 14 November 2015).

2. Dyllick, T.; Hockerts, K. Beyond the Business Case for Corporate Sustainability. Bus. Strategy Environ. 2002, 11, 130-141. [CrossRef]

3. Wharton School of the University of Pennsylvania. Why Companies Can No Longer Afford to Ignore Their Social Responsibilities. Available online: http:/ /business.time.com/2012/05/28/why-companies-can-nolonger-afford-to-ignore-their-social-responsibilities / (accessed on 4 June 2015).

4. Kiron, D.; Kruschwitz, N.; Haanaes, K.; Reeves, M.; Von Streng Velken, I. Sustainability Nears a Tipping Point. MIT Sloan Manag. Rev. 2012, 53, 68-75. [CrossRef] 
5. Gladwin, T.N.; Kennelly, J.J.; Krause, T. Shifting Paradigms for Sustainable Development: Implications for Management Theory and Research. Acad. Manag. Rev. 1995, 20, 874-907.

6. Waas, T.; Hugé, J.; Block, T.; Wright, T.; Benitez-Capistros, F.; Verbruggen, A. Sustainability Assessment and Indicators: Tools in a Decision-Making Strategy for Sustainable Development. Sustainability 2014, 9 , 5512-5534. [CrossRef]

7. Hahn, T.; Preuss, L.; Pinkse, J.; Figge, F. Cognitive frames in corporate sustainability: Managerial sensemaking with paradoxical and business case frames. Acad. Manag. Rev. 2015, 4015, 18-42. [CrossRef]

8. Perrott, B. The sustainable organisation: Blueprint for an integrated model. J. Bus. Strategy 2015, 35, 26-37. [CrossRef]

9. Hansmann, R.; Mieg, H.A.; Frischknecht, P. Principal sustainability components: Empirical analysis of synergies between the three pillars of sustainability. Int. J. Sust. Dev. World 2012, 19, 451-459. [CrossRef]

10. Linnenluecke, M.K.; Griffiths, A. Corporate sustainability and organizational culture. J. World Bus. 2010, 45, 357-366. [CrossRef]

11. Wagner, M. Corporate performance implications of extended stakeholder management: New insights on mediation and moderation effects. Ecol. Econ. 2011, 70, 942-950. [CrossRef]

12. Ameer, R.; Othman, R. Sustainability Practices and Corporate Financial Performance: A Study Based on the Top Global Corporations. J. Bus. Ethics 2012, 108, 61-79. [CrossRef]

13. Bell, J.; Soybel, V.E.; Turner, R.M. Integrating Sustainability into Corporate DNA. J. Corp. Account. Financ. 2012, 23, 71-82. [CrossRef]

14. Avery, G.; Bergsteiner, H. Sustainable Leadership Practices for Enhancing Business Resilience and Performance. Strategy Leadersh. 2011, 39, 5-15. [CrossRef]

15. Waas, T.; Huge, J.; Verbruggen, A.; Wright, T. Sustainable Development: A Bird's Eye View. Sustainability 2011, 3, 1637-1661. [CrossRef]

16. Harris, L.C.; Crane, A. The Greening of Organizational Culture: Management Views on the Depth, Degree and Diffusion of Change. J. Organ. Change Manag. 2001, 15, 214-234. [CrossRef]

17. Whittington, R. Completing the Practice Turn in Strategy research. Organ. Stud. 2006, 27, 613-632. [CrossRef]

18. Valente, M. Business Sustainability Embeddedness as a Strategic Imperative: A Process Framework. Bus. Soc. 2015, 54, 126-142. [CrossRef]

19. Avery, G.; Bergsteiner, H. How BMW Successfully Practices Sustainable Leadership Principles. Strategy Leadersh. 2011, 39, 12-18. [CrossRef]

20. Valente, M. Theorizing Firm Adoption of Sustaincentrism. Organ. Stud. 2012, 33, 563-591. [CrossRef]

21. Dunphy, D.C.; Griffiths, A.; Benn, S. Organizational Change for Corporate Sustainability: A Guide for Leaders and Change Agents of the Future; Routledge: Abingdon, UK, 2007; pp. 69-209.

22. Linnenluecke, M.K.; Russell, S.V.; Griffiths, A. Subcultures and Sustainability Practices: The Impact on Understanding Corporate Sustainability. Bus. Strategy Environ. 2009, 18, 432-452. [CrossRef]

23. Banerjee, S.B. Embedding Sustainability across the Organization: A Critical Perspective. Acad. Manag. Learn. Educ. 2011, 10, 719-731. [CrossRef]

24. Laszlo, C.; Zhexembayeva, N. Embedded Sustainability: The Next Big Competitive Advantage; Greenleaf Publishing: Sheffield, UK, 2011; pp. 75-98.

25. Willard, B. The 5-Stage Sustainability Journey. Available online: http://sustainabilityadvantage.com/2010/ 07/27/the-5-stage-sustainability-journey/ (accessed on 14 March 2016).

26. Crane, A.; Ruebottom, T. Stakeholder Theory and Social Identity: Rethinking Stakeholder Identification. J. Bus. Ethics 2011, 102, 77-87. [CrossRef]

27. Aragón-Correa, J.A.; Sharma, S. A Contingent Resource-Based View of Proactive Corporate Environmental Strategy. Acad. Manag. Rev. 2003, 28, 71-88.

28. Pinkse, J.; Hahn, T.; Figge, F.; Preuss, L. Trade-offs in corporate sustainability: You can't have your cake and eat it. Bus. Strategy Environ. 2010, 19, 217-229.

29. Banerjee, S.B.; Bonnefous, A. Stakeholder management and sustainability strategies in the French nuclear industry. Bus. Strategy Environ. 2011, 20, 124-140. [CrossRef]

30. Bonini, S.; Bove, A. Sustainability's Strategic Worth: McKinsey Global Survey Results. Mckinsey Insights: Mckinsey \& Company. Available online: http://www.mckinsey.com/insights/sustainability/ sustainabilitys_strategic_worth_mckinsey_global_survey_results (accessed on 20 October 2014). 
31. Pretorius, M.; le Roux, C. Determining the Embeddedness of Sustainability Claims in Strategizing: A Comparative Study of the ALSI 40 Companies. Acta Commer. 2012, 12, 123-149.

32. Hashmi, M.A.; Damanhouri, A.; Rana, D. Evaluation of Sustainability Practices in the United States and Large Corporations. J. Bus. Ethics 2015, 127, 673-681. [CrossRef]

33. Hallstedt, S.; Ny, H.; Rovert, K.; Broman, G. An approach to assessing sustainability integration in strategic decision systems for product development. J. Clean. Prod. 2010, 18, 703-712. [CrossRef]

34. Rode, J. Ethical Analysis for Evaluating Sustainable Business Decisions: The Case of Environmental Impact Evaluation in the Inambari Hydropower Project. Sustainability 2015, 7, 10343-10364. [CrossRef]

35. Hillestad, T.; Xie, C.; Haugland, S.A. Innovative corporate social responsibility; the founder's role in creating trustworthy corporate brand through 'green innovation'. JPBM 2010, 19, 440-451.

36. Wang, Y.; Ruhe, G. The Cognitive Process of Decision-Making. IJCN 2007, 1, 73-85. [CrossRef]

37. Perey, R. Making sense of sustainability through an individual interview narrative. Cult. Organ. 2015, 21, 147-173. [CrossRef]

38. Dahl, A.L. Achievements and gaps in indicators for sustainability. Ecol. Indic. 2012, 17, 14-19. [CrossRef]

39. Nambiar, P.; Chitty, N. Meaning Making by Managers: Corporate Discourse on Environment and Sustainability in India. J. Bus. Ethics 2014, 123, 493-511. [CrossRef]

40. Dyllick, T.; Muff, K. Clarifying the Meaning of Sustainable Business: Introducing a Typology from Business-as-Usual to True Business Sustainability. Organ. Environ. 2015. [CrossRef]

41. Simonovic, S.P.; Burn, D.H.; Lence, B.J. Practical sustainability criteria for decision-making. Int. J. Sustain. Dev. World 1997, 4, 231-244. [CrossRef]

42. Hahn, T.; Pinkse, J.; Preuss, L.; Figge, F. Tensions in Corporate Sustainability: Towards an Integrative Framework. J. Bus. Ethics 2015, 127, 297-316. [CrossRef]

43. Govindan, K.; Rajendran, S.; Sarkis, J.; Murugesan, P. Multi criteria decision making approaches for green supplier evaluation and selection: A literature review. J. Clean. Prod. 2015, 98, 66-83. [CrossRef]

44. Martin, L. Incorporating Values into Sustainability Decision-Making. J. Clean. Prod. 2015, 105, 1-11. [CrossRef]

45. Hahn, T.; Figge, F. Beyond the Bounded Instrumentality in Current Corporate Sustainability Research: Toward an Inclusive Notion of Profitability. J. Bus. Ethics 2011, 104, 325-345. [CrossRef]

46. Andersson, L.M.; Bateman, T.S. Individual environmental initiative: Championing natural environmental issues in U.S business organizations. Acad. Manag. J. 2000, 43, 548. [CrossRef]

47. McKenzie, J.; Woolf, N.; Van Winkelen, C.; Morgan, C. Cognition in strategic decision making: A model of non-conventional thinking capacities for complex situations. Manag. Decis. 2009, 47, 209-232.

48. Mittelstaedt, J.D.; Shultz, C.J.; Kilbourne, W.E.; Peterson, M. Sustainability as Megatrend: Two Schools of Macromarketing Thought. J. Macromarket. 2014, 34, 253-264. [CrossRef]

49. Tsai, W.; Chen, H.; Leu, J.; Chang, Y.; Lin, T.W. A product-mix decision model using green manufacturing technologies under activity-based costing. J. Clean. Prod. 2013, 57, 178-187. [CrossRef]

50. Chan, D.; Chen, S.; Hsu, C.; Hu, A.H. Identifying Strategic Factors of the Implantation CSR in the Airline Industry: The Case of Asia-Pacific Airlines. Sustainability 2015, 7, 7762-7783. [CrossRef]

51. Xia, X.; Govindan, K.; Zhu, Q. Analyzing internal barriers for automotive parts remanufacturers in China using grey-DEMATEL approach. J. Clean. Prod. 2015, 87, 811-825. [CrossRef]

52. Jarzabkowski, P.; Whittington, R. A strategy-as-practise approach to strategy research and education. J. Manag. Inq. 2008, 17, 282-286.

53. Decision Innovation. Theories for Making Decisions. Available online: http://www.decision-makingsolutions.com/decision-making-theories.html (accessed on 6 September 2015).

54. Pohekar, S.D.; Ramachandran, M. Application of multi-criteria decision-making to sustainable energy planning-A review. Renew. Sustain. Energy Rev. 2004, 8, 365-381. [CrossRef]

55. Georg, S.; Fussel, L. Making sense of greening and organizational change. Bus. Strategy Environ. 2000, 9, 175-185. [CrossRef]

56. Mantere, S.; Vaara, E. On the problem of participation in strategy: A critical discursive perspective. Organ. Sci. 2008, 19, 341-358. [CrossRef]

57. Weick, K.E.; Sutcliffe, K.M.; Obstfeld, D. Organizing and the Process of Sensemaking. Organ. Sci 2005, 16, 409-421. [CrossRef]

58. Eisenhardt, K.M. Building Theories from case study research. Acad. Manag. Rev. 1989, 14, 532-550. 
59. Yin, R.K. Case Study Research: Design and Methods; SAGE: Thousand Oaks, CA, USA, 2014; pp. 9-99.

60. Guba, E.G. Criteria for assessing the trustworthiness of naturalistic inquiries. ECTJ 1981, 29, 75-91.

61. Shenton, A.K. Strategies for ensuring trustworthiness in qualitative research projects. Educ. Inf. 2004, 22, 63-75.

62. Flyvbjerg, B. Five misunderstandings about case-study research. Qual. Inq. 2006, 12, 219-245. [CrossRef]

63. Charmaz, K. Constructing Grounded Theory; SAGE: London, UK, 2014; pp. 22-136.

64. Whittington, R. Practice perspectives on strategy: Unifying and developing a field. Acad. Manag. Proc. 2002, 1, C1-C6. [CrossRef]

65. Sharma, G.; Good, D. The Work of Middle Managers: Sensemaking and Sensegiving for Creating Positive Social Change. J. Appl. Behav. Sci. 2013, 49, 95-122. [CrossRef]

66. Steyn, M. Senior executives' perspectives of integrated reporting regulatory regimes as a mechanism for advancing sustainability in South African listed companies. South. Afr. Bus. Rev. 2014, 18, 142-174.

67. Visser, W.; Crane, A. Corporate Sustainability and the Individual: Understanding What Drives Sustainability Professionals as Change Agents. Available online: http://www.waynevisser.com/wp-content/uploads / 2010/02/paper_sustainability_individual_crane_wvisser.pdf (accessed on 12 October 2015).

68. Knauer, A.; Serafeim, G. Attracting Long-Term Investors through Integrated Thinking and Reporting: A Clinical Study of a Biopharmaceutical Company. J. Appl. Corp. Financ. 2014, 26, 57-64. [CrossRef]

69. Petrini, M.; Pozzebon, M. Integrating Sustainability into Business Practices: Learning from Brazilian Firms. Braz. Adm. Rev. 2010, 7, 362-378. [CrossRef]

70. Vaara, E.; Whittington, R. Strategy-as-Practice: Taking Social Practices Seriously. Acad. Manag. Ann. 2012, 6, 285-336. [CrossRef]

71. Elmualim, A.; Shockley, D.; Valle, R.; Ludlow, G.; Shah, S. Barriers and Commitment of Facilities Management Profession to the Sustainability Agenda. Build. Environ. 2010, 45, 58-64. [CrossRef]

72. Jarzabkowski, P.; Balogun, J.; Seidi, D. Strategising: The challenges of a practise perspective. Hum. Relat. 2007, 60, 5-27. [CrossRef]

73. Currie, G.; Brown, A.D. A narratological approach to understanding processes of organizing in a UK hospital. Hum. Relat. 2003, 563-586. [CrossRef]

74. Creswell, J.W. Qualitative Inquiry E Research Design; SAGE: Thousand Oaks, CA, USA, 2013; p. 22.

75. Guba, E.G.; Lincoln, Y.S. Competing paradigms in qualitative research. In Handbook of Qualitative Research; Denzin, N.K., Lincoln, Y.S., Eds.; SAGE: Thousand Oaks, CA, USA, 1994; p. 117.

76. Jabareen, Y. Building a Conceptual Framework: Philosophy, Definitions, and Procedure. Int. J. Qual. Methods 2009, 8, 49-62.

77. Princen, T. Speaking of sustainability: The potential of metaphor. Sustain. Sci. Pract. Policy 2010, 6, 60-65.

78. Barter, N.; Russell, S. Organisational metaphors and sustainable development: Enabling or inhibiting? Sustain. Account. Manag. Policy J. 2013, 4, 145-162. [CrossRef]

79. Bonn, I.; Fisher, J. Sustainability: The missing ingredient in strategy. J. Bus. Strategy 2011, 32, 5-14. [CrossRef]

80. Ioppolo, G.; Cucurachi, S.; Salomone, R.; Saija, G.; Shi, L. Sustainable Local Development and Environmental Governance: A Strategic Planning Experience. Sustainability 2016, 8, 180. [CrossRef]

81. Pollan, M. Our Decrepit Food Factories. Available online: http://michaelpollan.com/articles-archive/ourdecrepit-food-factories/ (accessed on 24 September 2015).

82. Murphy, K. The social pillar of sustainable development: A literature review and framework for policy analysis. Sustain. Sci. Pract. Policy 2012, 8, 15-29.

83. Vifell, Å.C.; Soneryd, L. Organizing matters: How 'the social dimension' gets lost in sustainability projects. Sustain. Dev. 2012, 20, 18-27.

84. Hind, P.; Wilson, A.; Lenssen, G. Developing leaders for sustainable business. Corp. Gov. 2009, 9, 7-20.

85. Haugh, H.M.; Talwar, A. How Do Corporations Embed Sustainability Across the Organization? Acad. Manag. Learn. Educ. 2010, 9, 384-396. [CrossRef]

86. Macmillan Dictionary Desire Path—Definition. Available online: http://www.macmillandictionary.com/ dictionary/british/desire-path (accessed on 30 November 2015).

87. Fenner, R.A.; Ainger, C.; Cruickshank, H.; Guthrie, P. Embedding sustainable development at Cambridge University Engineering Department. Int. J. Sustain. High. Educ. 2005, 6, 229-241.

88. Dawkins, C.; Ngunjiri, F.W. Corporate Social Responsibility Reporting in South Africa: A Descriptive and Comparative Analysis. J. Bus. Commun. 2008, 45, 286-307. [CrossRef] 
89. Aldama, L.R.P.; Amar, P.A.; Trostianki, D.W. Embedding corporate responsibility through effective organisational structures. Corp. Gov. 2009, 9, 506-516.

90. Zabarenko, D. How Corporate Leaders Make Sustainable Business Work for Their Companies. Available online: http:/ / sustainability.thomsonreuters.com/2012/10/25/executive-perspective-ceo-paul-polmanfrom-unilever-on-ending-the-three-month-rat-race/ (accessed on 15 December 2015).

91. Setthasakko, W. Barriers to Implementing Corporate Environmental Responsibility in Thailand: A Qualitative Approach. Int. J. Organ. Anal. 2009, 17, 169-183.

(C) 2016 by the authors; licensee MDPI, Basel, Switzerland. This article is an open access article distributed under the terms and conditions of the Creative Commons Attribution (CC-BY) license (http://creativecommons.org/licenses/by/4.0/). 